\title{
AiMT
}

Advances in Military Technology

Vol. 13, No. 2 (2018), pp. 223-235

ISSN 1802-2308, eISSN 2533-4123

DOI 10.3849/aimt.01195

\section{Finite Element Approach of Interior Permanent Magnet Motor Acoustics Noise}

\author{
P. Vyroubal", J. Maxa, T. Kazda and M. Mačák \\ Department of Electrical and Electronic Technology, Faculty of Electrical Engineering \\ and Communication, Brno University of Technology, Czech Republic
}

The manuscript was received on 16 May 2017 and was accepted after revision for publication on 7 September 2018.

\begin{abstract}
:
IPM (Interior Permanent Magnet) motors produce torque based on two different mechanisms. The first of them is permanent-magnet torque, which is generated by the flux linkage between the PM (Permanent Magnet) rotor field and the electro-magnetic field of the stator. It is the same torque as produced by SPM (Surface Permanent Magnet) motors, however, IPM designs produce another force known as reluctance torque. The second one, the shape and location of the slots in the rotor laminations are designed to channel magnetic flux so that even if the slots were left as air gaps, the rotor would experience a force to align the magnetic flux lines with those generated by the stator coils. IPM motors are now very popular in industrial and military applications by providing high power density and high efficiency compared to other types of motors. This paper presents the use of finite element method harmonic analysis for investigation of IPM motor acoustics noise. This method is useful for DC (Direct Current) motor designs in many industrial and military applications.
\end{abstract}

\section{Keywords:}

IPM motor, noise, finite element method, vibrations, model, acoustics, transient, electromagnetic.

\section{Introduction}

These days' trend is fastening the production rate while lowering the costs. This, of course, places high demands on the dynamic characteristics that affect overall machine behaviour. When lowering the costs, the manufacturers lighten the construction of the motor, which reflects on lowering its main frequency down to such values where it is

\footnotetext{
* Corresponding author: Department of Electrical and Electronic Technology, Faculty of Electrical Engineering and Communication, Brno University of Technology, Technická 10, 61600 Brno, Czech Republic. Phone: +420 5411461 49, e-mail:vyroubal@feec.vutbr.cz.
} 
much more probable that it will match the frequency of the induction signal. It causes vibrations, which lowers the quality of machining of the product and may even cause some damage to the machine. Last, but not least, the vibrations produce noise making the work with the machine unpleasant. Fig. 1 illustrates the various sources of noise generation in electric motors.

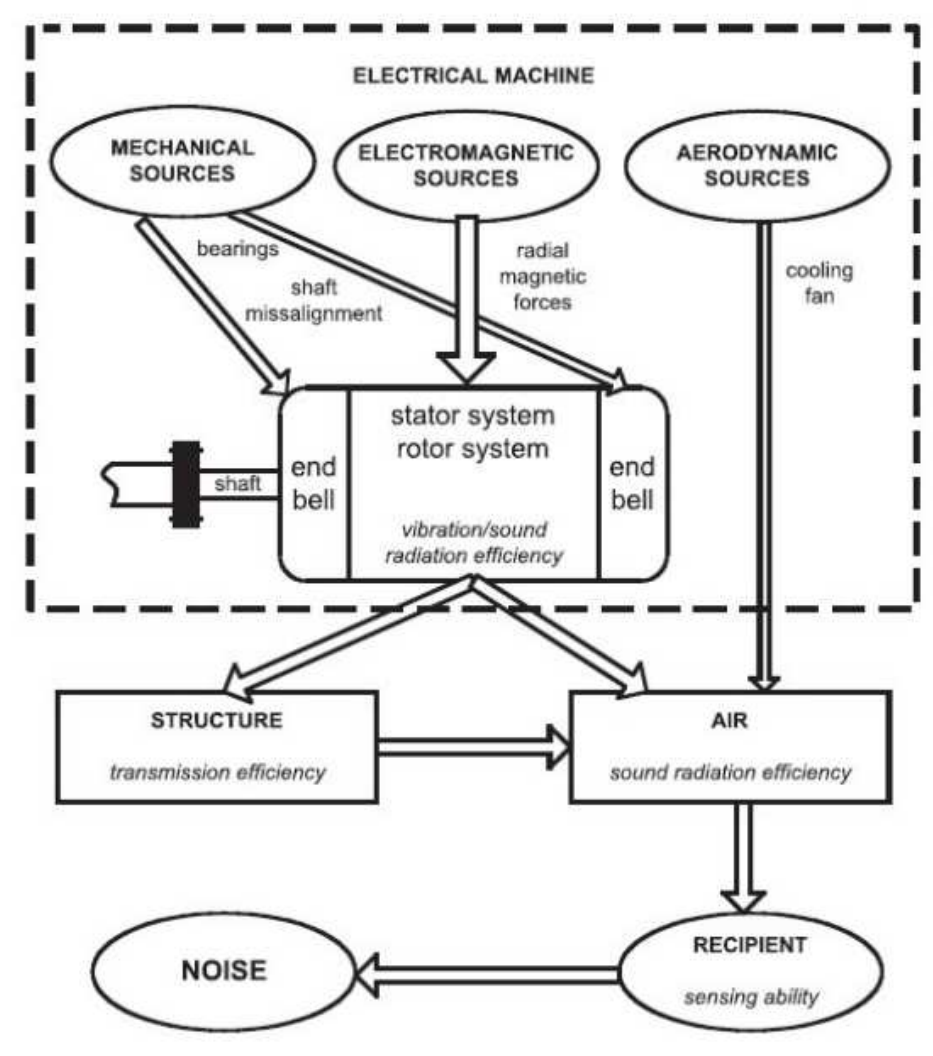

Fig. 1 Various sources of noise generation in electric motors

Resonation is a result of a forced oscillation, when the inducing frequency matches the own frequency of the system. This resonation results in a distinct oscillation amplitude increase, which may have fatal impact on the systems lifetime. There are also applications where the resonation is welcomed and we try to achieve it, however the process of designing or measuring a machine is not the case.

The modal analysis is a dynamics discipline, which uses the possibility of decomposition of a complex oscillating system into partial modal (also own) contributions for describing the oscillation characteristics and oscillating behaviour of engineering constructions (or more precisely their parts). Each contribution is characterized by modal frequency and modal shape of the oscillation [1]. The knowledge of these data helps to avoid collisions even in the phase of designing of the construction.

If the inducing frequency matches the own frequency of the construction, the resonation will occur and the machine could be badly damaged due to it. Modal analysis 
is also the base for some other analyses such as harmonic, transient or spectral analysis [2].

Harmonic analysis studies the response of a construction weighed by a harmonic induction signal. Harmonic analyses are used to determine the steady-state response of a linear structure to loads that vary sinusoidally (harmonically) with time, thus enabling us to verify whether or not the designs will successfully overcome resonance, fatigue, and other harmful effects of forced vibrations [3].

Fig. 2 illustrates generation of vibration and noise in multiphysics system.

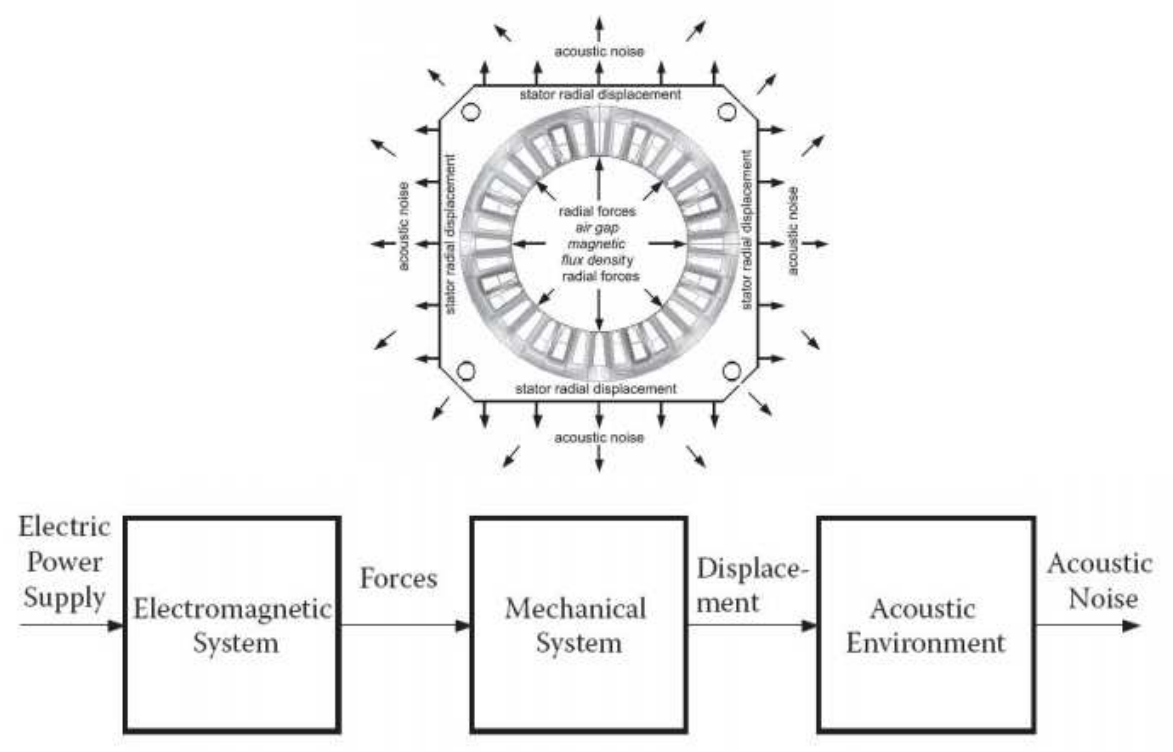

Fig. 2 Generation of vibration and noise

Estimation of noise and vibrations of electrical machines requires creating complex models with which to estimate the level of noise for given geometry, supply and load parameters. The model is composed of three main parts: electromagnetic, mechanical and acoustic.

\section{Noise sources in Electrical Machines}

There are three main types of sources:

1) Mechanical

2) Electromagnetic

3) Aerodynamic

\subsection{Mechanical Sources of Noise}

The first of the mechanical influences of noise is an angular and parallel shaft misalignment. Shaft misalignment produces a mechanical vibration with the frequency according to:

$$
f_{s}=2 n_{m}
$$

where $n_{m}$ is the shaft speed in rev/s. 
The second influence is dynamically unbalanced rotor. The cause may be unbalanced rotor, bent shaft, eccentricity, rubbing parts etc. These factors produce a vibrating frequency of once per revolution or multiple of the no. of revolution per cycle, according to:

$$
f_{s}=k n_{m},
$$

where $n_{m}$ is the shaft speed in rev/s and $k=1,2,3 \ldots$.

The next important factor is the loose stator stack. Loose stator lamination results in the following vibration frequency with the frequency side bands of $1000 \mathrm{~Hz}$. It can be described as:

$$
f_{\text {lam }}=2 f,
$$

where $f$ is the line frequency.

Other factors that influence the noise: stator stack related noise could be reduced by impregnation (encapsulation) of the stator stack, bearing noise and roller bearing. Rolling bearing generates mechanical impulses when the rolling element passes the defective groove, causing small radial movement of the rotor. The frequency at which the defect in the outer race causes an impulse when the ball or the roller passes the defective are of the race, according to:

$$
f_{o r}=\frac{N_{b}}{2} n_{m}\left(1-\frac{d_{b}}{D} \cos \alpha\right),
$$

where $D$ is the pitch diameter, $N_{b}$ in the number of rolling elements (balls), $d_{b}$ is the ball diameter and $\alpha$ is the contact angle of the rolling element.

\subsection{Electromagnetics Sources of Noise}

A possible source of electromagnetic noise is:

- Phase unbalanced

- Slot opening

- Input current waveform distortion

- Magnetic saturation

- Magnetostrictive expansion of core laminations

- Unbalanced magnetic pull

- Torque pulsation

Static and dynamic eccentricity error produces unbalanced magnetic pull resulting in bending of shaft. It reduces the mechanical stiffness of the shaft and first critical speed of the rotor due to increased magnetic pull. The consequence is unbalanced force due to diametrically asymmetric disposition of the stator slots and coils. The solution is the proper selection of slot/pole combination number will help in reducing the unbalanced magnetic pull.

Cogging torque of electrical motors is the torque due to the interaction between the permanent magnets of the rotor and the stator slots of a Permanent Magnet (PM) machine. It is also known as detent or 'no-current' torque. This torque is positiondependent and its periodicity per revolution depends on the number of magnetic poles and the number of teeth on the stator. Cogging torque is an undesirable component for the operation of such a motor. It is especially prominent at lower speeds, with the 
symptom of jerkiness. Cogging torque results in torque as well as speed ripple; however, at high speed the motor moment of inertia filters out the effect of cogging torque.

There are some ways to reduce cogging torque. As the most interesting seems to be the shaping of the stator slots. There are some useful shapes of slots, e.g. bifurcated slots (Fig. 3a), empty (dummy) slots (Fig. 3b), closed slots (Fig. 3c) and teeth with different width of active surface (Fig. 3d).

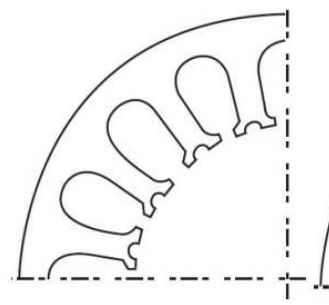

a)

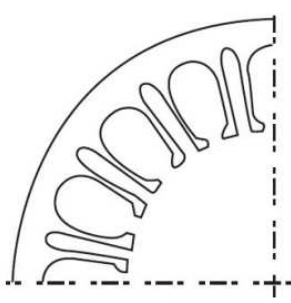

b)

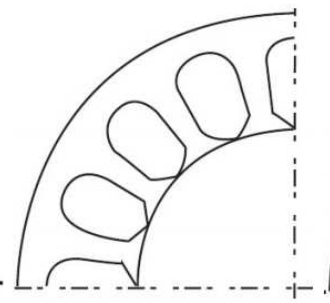

c)

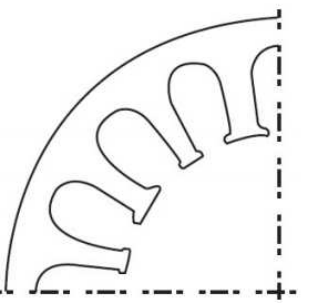

d)

Fig. 3 Different shapes of stator slots for cogging torque reduction

The next way is the shaping of permanent magnets. Decentred permanent magnets with bifurcated stator slot can help in reducing the cogging torque without much sacrifice of back-electromagnetic field. Decentred PMs with bifurcated stator slot can help in reducing the cogging torque without much sacrifice of back. Magnet may require a polygonal cross section of the core. In Fig. 4 the influence of decentred permanent magnets is shown.

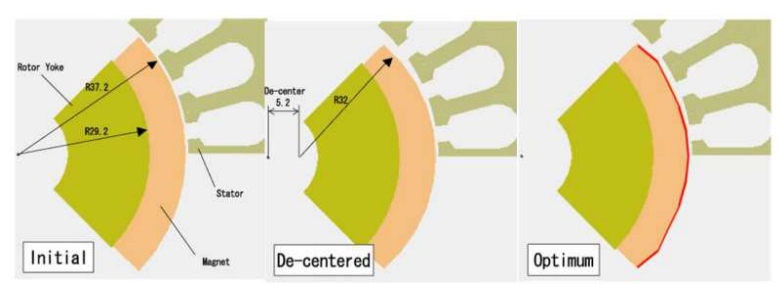

Fig. 4 Shaping of permanent magnet for cogging torque reduction

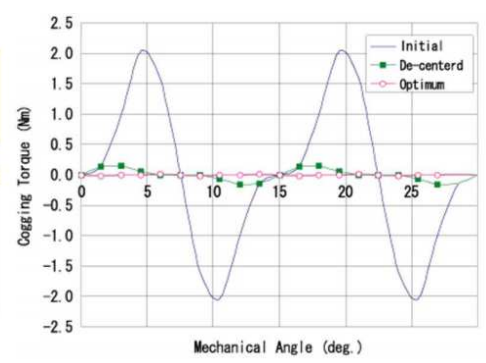

Mechanical Angle (deg.)

There are many factors that further affect the generation of noise caused by electromagnetic forces. Proper design of the motor can suppress some of these influences. However, we never completely get rid of these influences. This is due to the production process. Computer simulation appears to be a good tool for designing a specific solution.

\subsection{Aerodynamics Sources of Noise}

Aerodynamic noise refers to the noise generated by unsteady flow. It is also called aeroacoustics or flow noise. The aerodynamic source of noise is represented by the cooling system, meaning the airflow or the water circulating on the machine's housing or water jacket. 


\section{Mathematical - Physical Model}

\subsection{Model of Electromagnetic Field}

As the first part of presented model, the electromagnetic model is responsible for determining the electromagnetic excitation of the mechanical structure. It is assumed that only the radial component of magnetic force applied to the stator causes the crucial stator deflections and noise emission [4].

The inducing harmonic force is given by the strength of the electromagnetic field, which emerge on the motors stator, respectively by the forces' real and imaginary part transport [5]. When solving non-stationary (changing in time) electromagnetic field, it is necessary to use full-length Maxwell equations, whose fundamental form in the differential form is:

$$
\operatorname{rot} \mathbf{H}=\mathbf{J}+\frac{\partial \mathbf{D}}{\partial t}, \operatorname{rot} \mathbf{E}=-\frac{\partial \mathbf{B}}{\partial t}, \operatorname{div} \boldsymbol{D}=0, \operatorname{div} \boldsymbol{B}=0,
$$

where $\boldsymbol{H}$ is the vector of magnetic field $[\mathrm{A} / \mathrm{m}], \boldsymbol{D}$ is the vector of electric induction $\left[\mathrm{C} / \mathrm{m}^{2}\right], \boldsymbol{E}$ is the vector of intensity of electric field, $\boldsymbol{B}$ is the vector of the magnetic induction $[\mathrm{T}], \boldsymbol{J}$ is the vector of current density $\left[\mathrm{A} / \mathrm{m}^{2}\right]$.

The continuity equation is in the following form:

$$
\operatorname{div} \boldsymbol{J}+\frac{\partial \rho}{\partial t}=0
$$

where $\rho$ is the volume density of a free charge $\left[\mathrm{C} / \mathrm{m}^{3}\right]$.

\subsection{Model of mechanical deformation}

For the mechanical deformation, the model for the linear theory of elasticity applies:

$$
\boldsymbol{F}_{s}+\nabla \cdot \boldsymbol{T}=0
$$

where $\boldsymbol{T}$ are the components of the stress tensor, which are a linear combination of components of the deformation tensor and $\boldsymbol{F}_{s}$ is the total volume force expressed as:

$$
\boldsymbol{F}_{s}=\boldsymbol{f}_{0}+\boldsymbol{f}+\rho \frac{\partial^{2} \boldsymbol{u}}{\partial^{2} t}, t \in(0, T), x \in \Omega_{s},
$$

where $\rho \rho$ is the density of the material in specific state of the element and $\boldsymbol{u}$ is the vector of displacement, $t$ is the time. Force $f$ represents the vector of volume forces. Relative volume force $f$ formed only by current and magnetic fields is expressed as a vector product:

$$
f=J \times B
$$

\subsection{Model of Mechanical Oscillation}

Forced oscillation can be described by a motion equation, where its right side represents the induction force that changes in time:

$$
\boldsymbol{M} \frac{\partial^{2} \boldsymbol{q}}{\partial t^{2}}+\boldsymbol{B} \frac{\partial \boldsymbol{q}}{\partial t}+\boldsymbol{K} \boldsymbol{q}=\boldsymbol{F}(t)
$$


where $\frac{\partial^{2} \boldsymbol{q}}{\partial t^{2}}$ is the acceleration vector, $\frac{\partial \boldsymbol{q}}{\partial t}$ is the velocity vector, $\boldsymbol{q}$ is the position vector, $\boldsymbol{M}$ is the mass matrix, $\boldsymbol{B}$ is the matrix of damping, $\boldsymbol{K}$ is the stiffness matrix and $\boldsymbol{F}(t)$ is the vector of harmonic excitation forces.

After several mathematical modifications [6], we will receive the formula for the amplitude of a forced oscillation dependant on the frequency of the inducing force:

$$
f_{A}=\frac{F_{0}}{k \sqrt{\left(1-\frac{\omega^{2}}{\omega_{0}^{2}}\right)^{2}+\left(2 b_{r} \frac{\omega}{\omega_{0}}\right)^{2}}},
$$

where $b_{r}$ is the damping, $\omega$ is the angle velocity, $\omega_{0}$ is the own angle frequency of non-dampened oscillation.

$$
b_{r}=\frac{\delta}{\omega_{0}} .
$$

\subsection{Model of Acoustic Noise}

In acoustic fluid-structural interaction problems, the structural dynamics equation must be considered along with the Navier-Stokes equations of fluid momentum and the flow continuity equation. The final form of acoustic noise equation is reduced to the following inhomogeneous Helmholtz equation [7] and [8]:

$$
\nabla\left(\frac{1}{\rho_{0}} \nabla p\right)-\frac{\omega^{2}}{\rho_{0} c^{2}} p+j \omega \nabla\left[\frac{4 \mu}{3 \rho_{0}} \nabla\left(\frac{1}{\rho_{0} c^{2}} p\right)\right]=-j \omega\left(\frac{Q}{\rho_{0}}\right)+\nabla\left[\frac{4 \mu}{3 \rho_{0}} \nabla\left(\frac{Q}{\rho_{0}}\right)\right],
$$

where $\omega=2 \pi f$ and $f$ is the frequency of the pressure oscillations, $j$ is the imaginary unit, $\mu$ is the dynamic viscosity of fluid, $p$ is the acoustic pressure $(p(x, y, z, t)), \rho_{0}$ is the fluid density, $c$ is the speed of sound in fluid and $Q$ is the mass source.

\section{Results and Discussion}

ANSYS Maxwell uses the Finite Element Method (FEM) to solve Maxwell's electro-magnetic field equations. In order to obtain the set of algebraic equations to be solved, the geometry of the problem is discretized automatically into basic platonic solids (e.g. Triangles in 2D \& Tetrahedrons in 3D).

The assembly of all tetrahedrons/triangles is referred to as the finite element mesh of the model or simply, the mesh. The model of IPM motor was created using ANSYS Maxwell software. All pre-defined parts were designed in RMxprt. Model of the motor is showed in Fig. 5; the driver circuit is in Fig. 6.

Tab. 1 contains the basic parameters of the motor and the parameters for transient analysis.

The transient analysis was created for the investigation of currents for each phase of the IPM motor. Fig. 7 shows Winding currents vs. time.

Fig. 8 shows the stator shape used for harmonic and acoustic analysis 


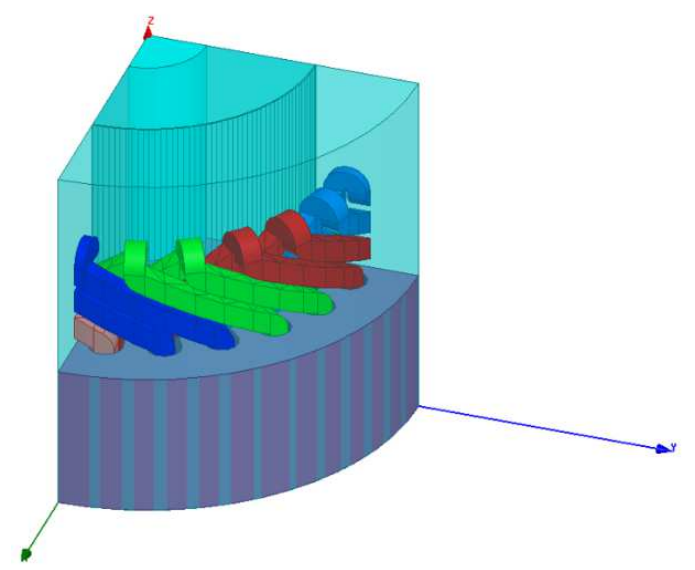

Fig. 5 1/4 of IPM motor 3D FEM model.

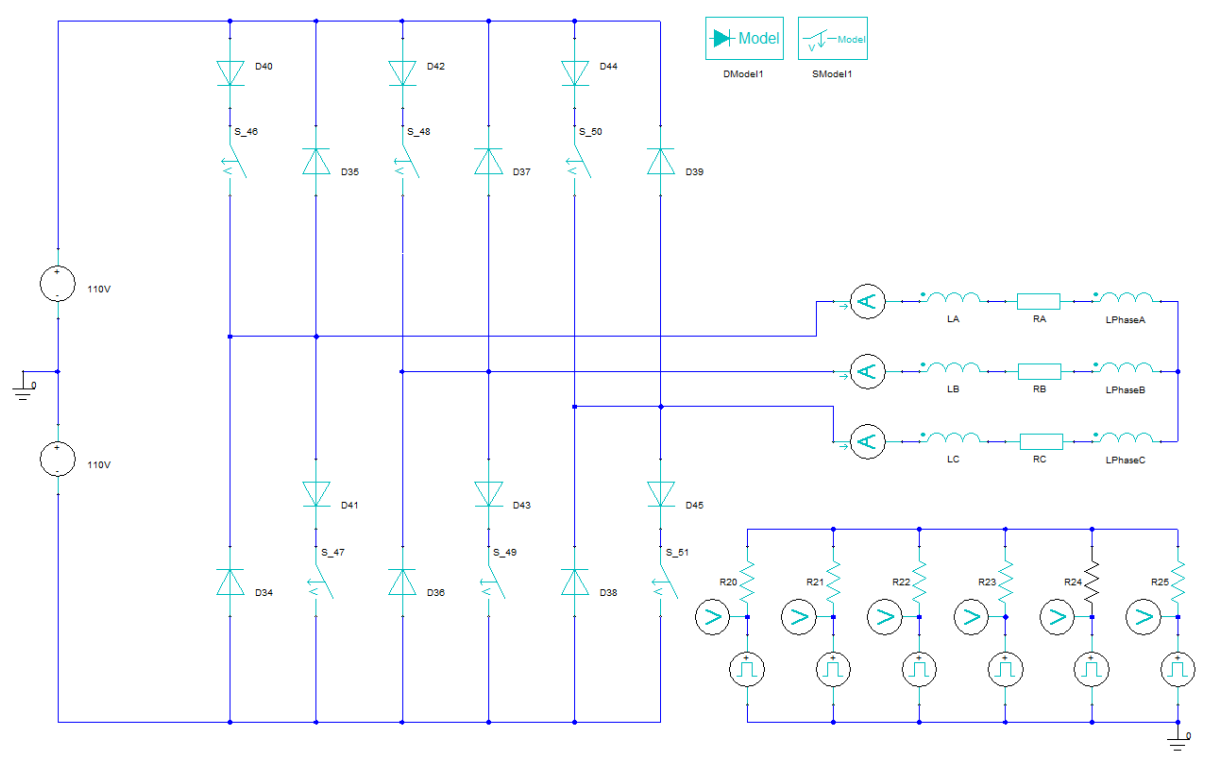

Fig. 6 Driver circuit for IPM motor.

Tab. 1 Motor parameters.

\begin{tabular}{|l|c|}
\hline Source type & DC \\
\hline Rated output power & $750 \mathrm{~W}$ \\
\hline Rated Voltage & $120 \mathrm{~V}$ \\
\hline Rated speed & $2200 \mathrm{rev} / \mathrm{min}$ \\
\hline Operating temperature & $75^{\circ} \mathrm{C}$ \\
\hline Stop time & $0.04 \mathrm{~s}$ \\
\hline Time step & $0.0002 \mathrm{~s}$ \\
\hline
\end{tabular}




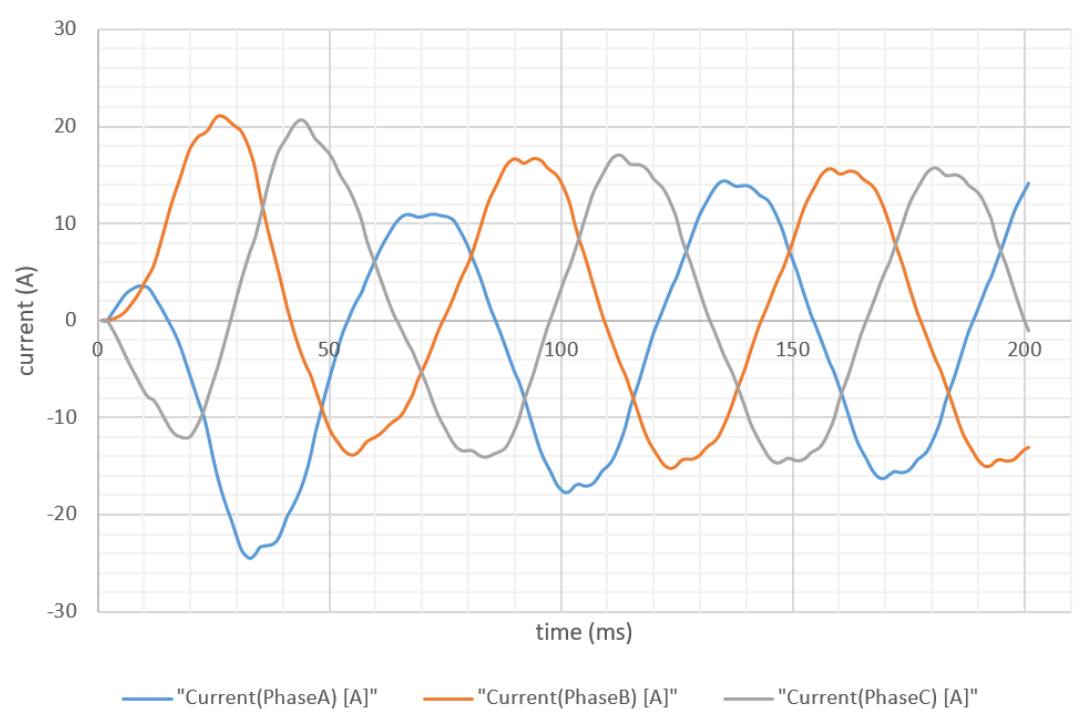

Fig. 7 Winding currents vs. time.

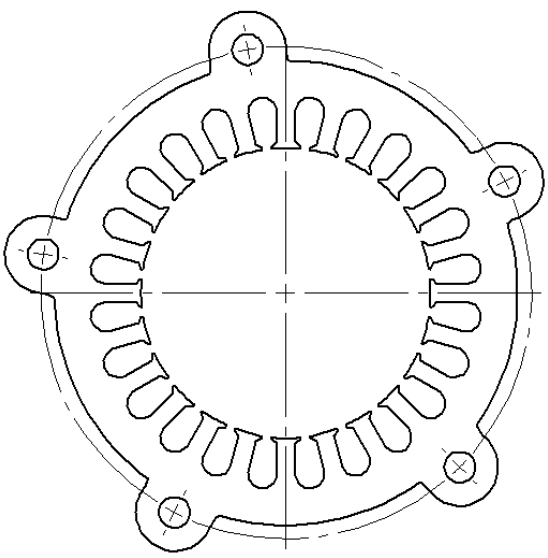

Fig. 8 Stator shape used for harmonic and acoustic analysis.

Harmonic analysis examines the construction response to a stress from harmonically induced signal. In this case, the induced signals' frequency was examined in the range from $0 \mathrm{~Hz}$ to $3000 \mathrm{~Hz}$ linearly spread into 50 steps. As a result, we obtained radial and tangential components of deformation of stator in specific frequency [6-8, $10]$.

The relation between the amplitude of forced oscillations and frequency is called the amplitude-frequency characteristics. Similarly, the relation between the change of phase shift (in dampened systems) and frequency is called the phase characteristics.

These characteristics are considered as a base when working with mechanic systems. Amplitude and phase characteristics applied on one stator tooth are shown in the following Fig. 9 (phase angle) and Fig. 10 (amplitude). 


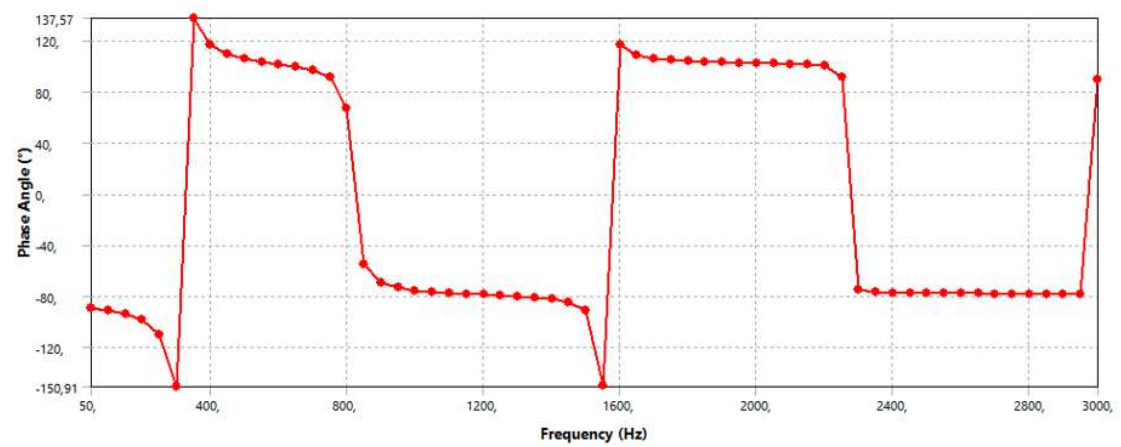

Fig. 9 Phase angle of frequency response

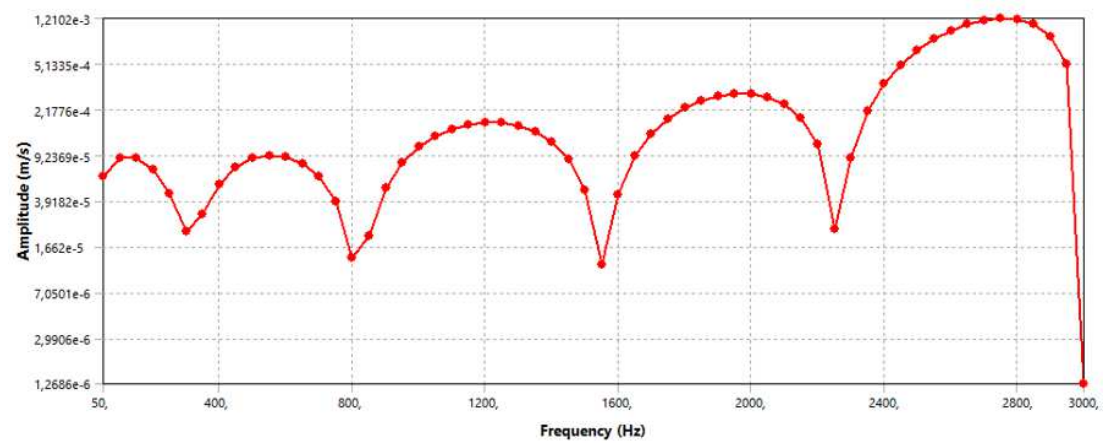

Fig. 10 Amplitude of frequency response

Fig. 11 shows radial and tangential deformation on the stator. Similarly Fig. 12 shows radial and tangential stress.
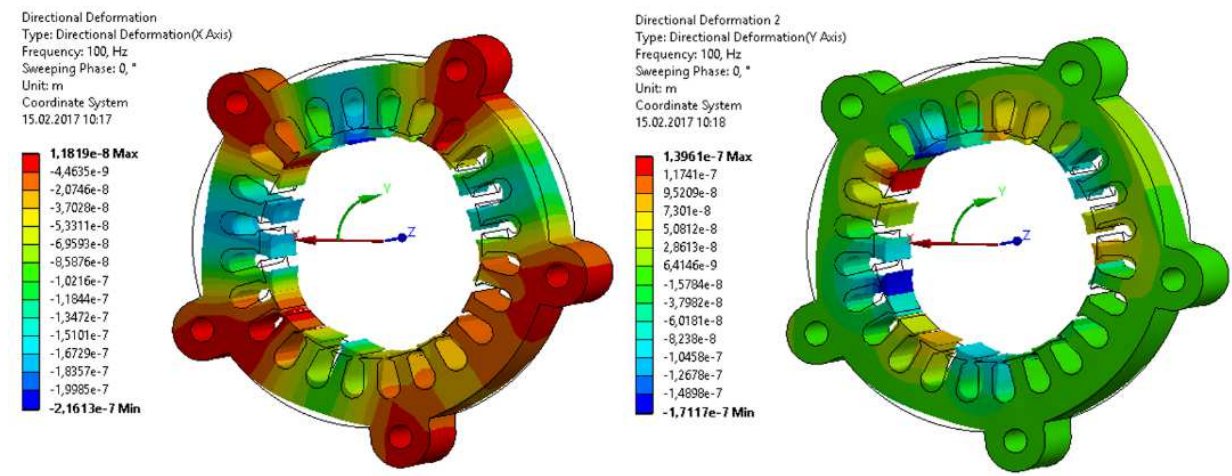

Fig. 11 Radial and tangential deformation by $100 \mathrm{~Hz}$

In a specific moment, we can find areas where more oscillating points cluster and as the opposite, we can find areas with lower molecular density. In gases and liquids these are the places of higher and lower pressure.

This thickening and dilution relates to the change of total static air pressure. In the next figure, the total static pressure is marked out as a sum of the mean barometric pressure and acoustic pressure. 

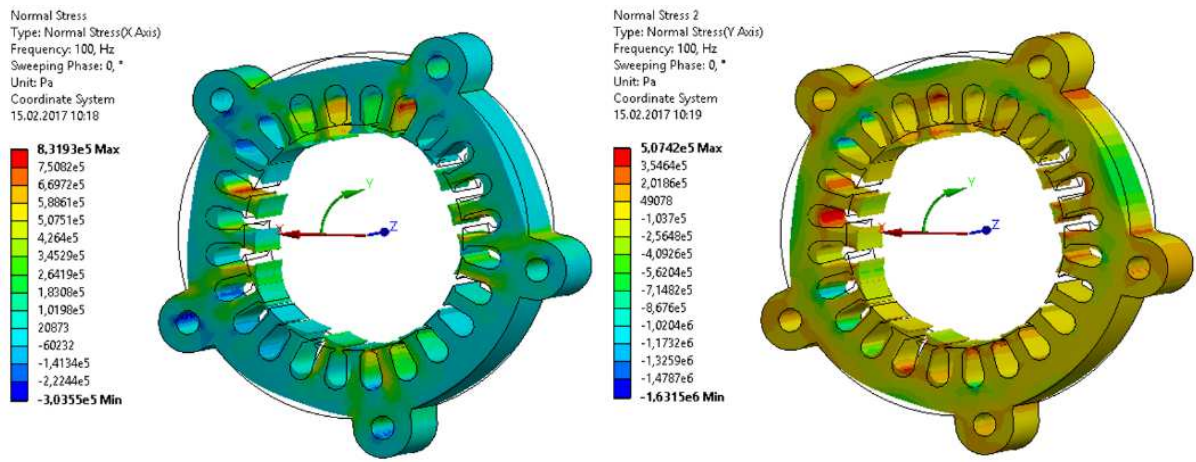

Fig. 12 Radial and tangential stress by $100 \mathrm{~Hz}$

Fig. 13 shows the acoustic pressure on the cross section of the surrounding environment.

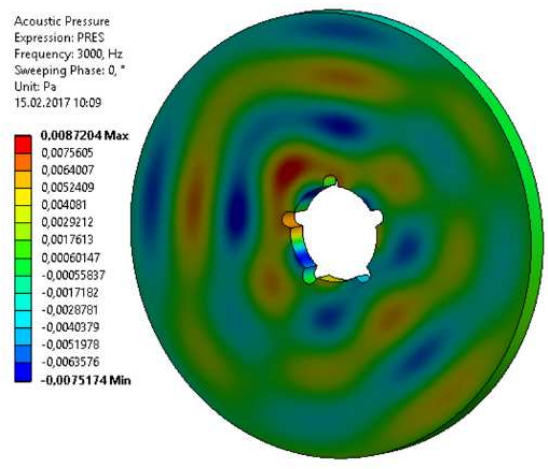

Fig. 13 Acoustic pressure by frequency of $3000 \mathrm{~Hz}$

There is a view of the acoustic pressure by the frequency of $3 \mathrm{kHz}$. Fig. 14 shows the sound pressure level of noise vibrations in the cross section of surrounding environment (the frequency of $3 \mathrm{kHz}$ ).

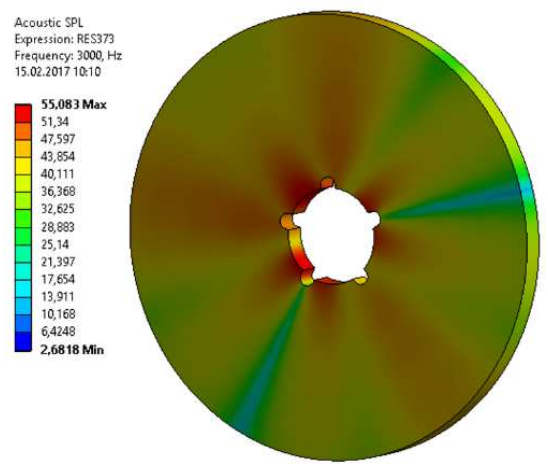

Fig. 14 Sound pressure level (SPL) by frequency of $3000 \mathrm{~Hz}$ 


\section{Conclusion}

The harmful effects of noise on human have led numerous developed countries to apply some legislative steps, resulting in lots of laws, standards and other legal regulations which protect people from excessive noise and vibrations in the field of municipal hygiene, and in workplaces.

When electrical rotatory machines are running, they always produce noise related to the movement of various parts of the machine. For electric rotatory machines, we divide the noise into three groups: electromagnetic, mechanic and ventilating considering their origin.

Electromagnetic noise takes its form in the frame shaking or the shaking of another part of the machine caused by electromagnetic forces, while the frequency spectrum is discrete. Mechanic noise has a mixed character, since it is caused by bearing or imbalance of rotating parts of the machine. Ventilation noise is caused mainly by the running of the ventilator of the machine and by the cooling air passing through its cooling gap.

When using appropriate analytical and numerical computing programs and using the finite element method, it is possible to lower the pulsation of the torque momentum to minimum.

\section{Acknowledgement}

This research work has been carried out in the Centre for Research and Utilization of Renewable Energy (CVVOZE). Authors gratefully acknowledge financial support from the Ministry of Education, Youth and Sports of the Czech Republic under NPU I programme (project No. LO1210).

\section{References}

[1] POLLOCK, C. and WU, C.-Y. Acoustic Noise Cancellation Techniques for Switched Reluctance Drives. IEEE Transactions on Industry Applications, 1997, vol. 33, no. 2, p. 477-484. DOI 10.1109/28.568013.

[2] HWANG, S.-M. et al. Influence of Magnetic Force Upon Noise of an IPM Motor Used in Compressor. IEEE Transactions on Magnetics, 2006, p. 3494 - 3496. ISSN 0018-9464. DOI 10.1109/TMAG.2006.880086.

[3] COLBY, R.S., MOTTIER, F.M. and MILlER, T.J.E. Vibration Modes and Acoustic Noise in a Four-phase Switched Reluctance Motor. IEEE Transactions on Industry Applications, 1996, vol. 32, no. 6, p. 1357-1364. ISSN 0093-9994. DOI 10.1109/28.556639.

[4] LI, Y.B., HO, S.L., FU, W.N. and XUE, B.F. Analysis and Solution on Squeak Noise of Small Permanent-Magnet DC Brush Motors in Variable Speed Applications. IEEE Transactions on Magnetics. 2009, vol. 45, no. 10, p. 4752-4755.

[5] STRATTON, J.A. Electromagnetic Theory. New Jersey: Hoboken, 2007.

[6] ANSYS Mechanical APDL. Coupled-Field Analysis Guide. Canonsburg, 2015, p. 252.

[7] BESBES, M., PICOD, C., CAMUS, F. and GABSI, M. Influence of Stator Geometry Upon Vibratory Behaviour and Electromagnetic Performances of 
Switched Reluctance Motors. IEE Proceedings - Electric Power Applications. 1998, vol. 145, no. 5, p. 462-468. DOI 10.1049/ip-epa:19982163.

[8] Theory Reference for Mechanical APDL and Mechanical Applications: ANSYS, Inc. Canonsburg, PA, 2017.

[9] HE, G., HUANG, Z. and CHEN, D. Two-Dimensional Field Analysis on Electromagnetic Vibration-and-Noise Sources in Permanent-Magnet Direct Current Commutator Motors. IEEE Transactions on Magnetics. 2011, vol. 47, no. 4, p. 787-794. DOI 10.1109/TMAG.2010.2103382.

[10] BUJACZ, S. and NIEZNANSKI, J. Estimation of Acoustic Noise of P.M. Motor by Multi-physical Model. In 2011 IEEE International Symposium on Industrial Electronics. Gdansk: IEEE, 2011, p. 597-600. DOI 10.1109/ISIE.2011.5984225. 